\title{
Effect of Oxotremorine and Epinephrine on Lung Surfactant Secretion in Neonatal Rabbits
}

\author{
M. M. ABDELLATIF AND M. HOLLINGSWORTH(36) \\ Departments of Pharmacology, Materia Medica, and Therapeutics and Child Health, University of Manchester \\ Medical School, Stopford Building. Oxford Road, Manchester M13 9PT. England
}

\section{Summary}

The phosphatidylcholine (PC) content (mg/g dry lung weight; mean \pm S.E.) of lung washes of 1 to 3-day-old rabbits was significantly greater $\mathbf{3 0} \mathrm{min}$ after the injection of the muscarinic agonist oxotremorine $(0.2 \mathrm{mg} / \mathrm{kg} ; 50.5 \pm 2.9 \mathrm{mg} / \mathrm{g} ; 2 P<0.01)$ or epinephrine $(50 \mu \mathrm{g} / \mathrm{kg} ; 78.0 \pm 14.8 \mathrm{mg} / \mathrm{g} ; 2 P<0.001)$ than saline $(25.7 \pm 1.9 \mathrm{mg} / \mathrm{g})$. Injection of atropine $(2 \mathrm{mg} / \mathrm{kg})$, dl-propranolol $(1 \mathrm{mg} / \mathrm{kg})$ but not d-propranolol $(1 \mathrm{mg} / \mathrm{kg})$ at $40 \mathrm{~min}$ or adrenalectomy at $45 \mathrm{~min}$ before killing abolished the increase produced by oxotremorine $(2 P<0.001)$. Also, dl-propranolol antagonized the increase produced by epinephrine. Palmitic and myristic acids were the major fatty acids in the lung wash $P C$ of control and oxotremorine-treated rabbits. The residual lung tissue $P C$ content following atropine $(2 \mathrm{mg} / \mathrm{kg} ; 104.4 \pm 18.5 \mathrm{mg} / \mathrm{g})$ was significantly greater $(2 P<0.05)$ than following saline $(72.6 \pm 6.0 \mathrm{mg} / \mathrm{g})$ but not different $(2 P>0.05)$ in other treatment groups. The total lung content of $P C$ was $55 \%$ greater $(2 P<0.001)$ than controls $30 \mathrm{~min}$ after epinephrine $(50 \mu \mathrm{g} / \mathrm{kg})$.

The surface activity of lung washes ( $\mathrm{mg} / \mathrm{g}$ dry lung weight; mean \pm S.E.), assayed on a surface tension balance using dipalmitoylphosphatidylcholine as standard, was significantly greater $(2 \mathrm{P}<$ 0.05) $30 \mathrm{~min}$ following injection of oxotremorine $(0.2 \mathrm{mg} / \mathrm{kg} ; 73.8$ $\pm 9.9 \mathrm{mg} / \mathrm{g})$ or epinephrine $(50 \mu \mathrm{g} / \mathrm{kg}: 72.2 \pm 10.2 \mathrm{mg} / \mathrm{g})$ than saline $(42.8 \pm 2.0 \mathrm{mg} / \mathrm{g})$. Ten-min infusions of oxotremorine $(0.34$ $\mu \mathrm{g} / \mathrm{ml}$ ) into isolated, ventilated, perfused neonatal rabbit lung preparations failed to alter the $\mathrm{PC}$ content of the subsequent wash, but this was significantly $(2 P<0.05)$ raised from 3.7 ( \pm $0.8)$ to $4.8( \pm 0.8) \mathrm{mg} / \mathrm{g}$ dry lung wt by a $10 \mathrm{~min}$ infusion of epinephrine $(3.4 \mu \mathrm{g} / \mathrm{ml})$.

\section{Speculation}

Alteration of the rate of secretion of lung surfactant into alveoli may control the rate of biosynthesis. Disorders of lung surfactant secretion may be involved in the pathogenesis of respiratory distress syndrome.

\section{INTRODUCTION}

There is now substantial evidence that lung surfactant is mainly composed of phospholipids, particularly dipalmitoyl phosphatidylcholine (DPPC) (21), synthesized in type 2 pneumocytes and stored as osmiophilic lamellar bodies (OLB) $(4,15)$. There are several morphologic studies describing discharge of these OLB into alveoli $(3,5,29)$. In other tissues where substances are synthesized and stored before release, there are discrete physiologic processes controlling secretion as well as synthesis $(22,32)$. Secretion of stored lung surfactant into alveoli may be a controlled process; possible modulators include agonists at muscarinic receptors and $\beta$-adrenoceptors and ventilation.

Goldenberg et al. (16) described enhanced expulsion of OLB into alveoli in adult rats following injection of the muscarinic agonist pilocarpine. Pilocarpine injection has also been shown to decrease the number of OLB per type 2 pneumocyte, increase the phospholipid content of lung lavages in adult rats (24), and increase the air retention on deflation of fetal rabbit lungs $(7,8)$. Morgan and Morgan (23) demonstrated earlier appearance and higher specific activity of $\left[{ }^{14} \mathrm{C}\right]$ palmitate in disaturated phosphatidylcholines (PC's) in lavage fluid of adult rats following pilocarpine. These observations are compatible with an increase in surfactant secretion after pilocarpine. Corbet et al. (8) have suggested that pilocarpine acts indirectly to increase the static compliance of fetal rabbit lungs because its effect could be antagonized by large doses of phenoxybenzamine or propranolol. More direct evidence of a role for muscarinic receptors mediating surfactant secretion has come from studies showing enhanced release of radiolabeled PC from explants of fetal rat lungs (27) by prolonged incubation with pilocarpine and from a culture of cell line A549, whose cells resemble type 2 pneumocytes, by acetylcholine, and by carbachol (31).

$\beta$-adrenoceptors may also be involved in controlling lung surfactant secretion. Injection of isoproterenol into adult rats increased the phospholipid content of lung lavages and reduced the number of OLB per type 2 pneumocyte (24). These effects were antagonized by propranolol. Three to $5 \mathrm{hr}$ after isoxsuprine injection into fetal rabbits, there were increases in lung static compliance $(12,34)$ and lecithin/sphingomyelin ratio and surface activity of pulmonary fluid and decreases in the number of OLB per type 2 pneumocyte (12). Terbutaline, a $\beta$-adrenoceptor agonist, increased the release of ${ }^{14} \mathrm{C}$-disaturated $\mathrm{PC}$ from adult rat type 2 alveolar cells in vitro (11), providing the most direct evidence that secretion is sensitive to $\beta$-adrenoceptor agonists.

Increased minute ventilation in lightly anesthetised adult rabbits raised the phospholipid content of lung washes, and this action could be antagonized by atropine, propranolol, sotalol, indomethacin, or sodium meclofenamate $(25,26)$. This suggests the involvement of muscarinic receptors, $\beta$-adrenoceptors, and prostaglandins in ventilation-induced surfactant secretion.

We have therefore examined the effect of a selective muscarinic agonist, oxotremorine (9), on lung surfactant secretion by measuring the PC content and surface activity in lung washes in neonatal rabbits and the residual lung tissue PC content at a short time interval (30 $\mathrm{min})$ after injection of this drug and after various pretreatments. Furthermore, the effect of oxotremorine and epinephrine have been studied on a perfused, isolated, ventilated lung preparation. Preliminary results have been published $(1,2)$.

\section{MATERIALS AND METHODS}

One- to 3-day-old Dutch rabbits (Nottingham University, United Kingdom) were used. They were given injections of the drugs or saline at the doses (in terms of base) and times before killing given in Table 1 . Other groups of rabbits were given injections of oxotremorine or saline $15 \mathrm{~min}$ after bilateral adrenalectomy under ether anesthesia. 


\section{ISOLATED LUNG PREPARATION}

All rabbits, whether pretreated or not, had their isolated lungs perfused and ventilated (1). Each rabbit was tracheotomized under sodium pentobarbitone $(45 \mathrm{mg} / \mathrm{kg})$ anesthesia, its pulmonary artery was cannulated, and the weighed lungs were removed into a well-sealed, water-heated $\left(38^{\circ} \mathrm{C}\right)$ perspex box with the tracheal cannula open to the air. The lungs were perfused with KrebsHenseleit solution $\left(37^{\circ} \mathrm{C}\right)$ bubbled with $95 \%$ oxygen and $5 \%$ carbon dioxide at $2.9 \mathrm{ml} / \mathrm{min}$ via the pulmonary artery. Successful perfusion was assessed by removal of blood from the lungs. The perfusate collected in the lung chamber, maintained the humidity, and was removed at 5-min intervals. The box was evacuated 140 times/min to a negative pressure of about $37 \mathrm{~mm} \mathrm{Hg}$ using a small animal ventilator (Scientific Research Instruments, Ltd.). In most experiments, at 5 -min intervals ventilation was stopped, $1.5 \mathrm{ml}$ of saline were injected slowly into the lungs via the tracheal cannula, and after $1 \mathrm{~min}$, as much saline as possible was withdrawn to produce a lung wash. A total of 6 successive washes from each rabbit were combined. These and samples of the residual lung tissues were stored at $-20^{\circ} \mathrm{C}$ until assayed chemically, or their surface activity was measured. Other weighed samples of residual lung tissues were dried at $150^{\circ} \mathrm{C}$ for 2 days to determine lung dry weight.

In a further group of in vitro experiments, the first four lung washes were discarded. Oxotremorine $(0.34 \mu \mathrm{g} / \mathrm{ml})$, epinephrine $(3.4 \mu \mathrm{g} / \mathrm{ml})$, or saline was added to the infusing $\mathrm{Krebs}$ solution for $10 \mathrm{~min}$ after the fifth wash. Following a further 5 -min period with Krebs solution only, the sixth wash was obtained. The fifth and sixth washes were assessed individually for their PC contents.

\section{CHEMICAL ASSAYS}

Aliquots $(0.5 \mathrm{ml})$ of lung washes were assayed in duplicate for their PC content. Following three extractions with chloroform/ methanol $(2 / 1, v / v)$, the pooled chloroform layer was evaporated at $50^{\circ} \mathrm{C}$ under nitrogen. After separation of PC by thin-layer chromatography on silica gel (Merck $F_{254}$ ) using chloroform/ methanol/glacial acetic acid/water $(75 / 25 / 7 / 3, \mathrm{v} / \mathrm{v} / \mathrm{v} / \mathrm{v})$ as solvent. PC was measured by phosphorus assay (6) using DPPC as standard. The minimum quantity of $P C$ that could be readily distinguished from blanks was $10 \mu \mathrm{g}$. Samples of lung tissue were assayed in a similar manner after homogenisation for $2 \mathrm{~min}$ in chloroform/methanol $(3 / 1 ; \mathrm{v} / \mathrm{v})$ using an Ultra-Turrax type TP $18 / 2$ homogenizer and filtration. Recovery of a $60 \mu \mathrm{g}$ standard of DPPC was $82.2 \pm 2.7 \%$ (mean \pm S.E.; $n=20$ ). Phosphatidylcholine content was corrected for procedural losses and standardized per $g$ of dry lung weight.

Further samples of lung washes from two oxotremorine $(0.2$ $\mathrm{mg} / \mathrm{kg}$ ) and two saline-pretreated rabbits were subjected to twodimensional thin-layer chromatography using chloroform/methanol/ammonia, $(65 / 35 / 5 ; \mathrm{v} / \mathrm{v} / \mathrm{v})$ and chloroform/acetone/methanol/glacial acetic acid/water $(50 / 20 / 10 / 10 / 5 ; \mathrm{v} / \mathrm{v} / \mathrm{v} / \mathrm{v} / \mathrm{v})$ as first and second solvents, respectively. Phosphomolybidic acid and stannous chloride or charring were used to identify the phospholipids present. After location with stannous chloride, the PC spots were removed and digested with methanolic sodium methoxide, and the methyl esters of the fatty acids were separated by gasliquid chromatography (19). The relative peak areas were used to determine the proportion of each fatty acid in PC.

\section{SURFACE ACTIVITY}

Measurement of surface activity were made using an apparatus based on the Wilhelmy surface tension balance (Ref. 15; Fig 1a). This consisted of a platinum plate hung from a torsion arm and dipping in a $0.9 \%(\mathrm{w} / \mathrm{v})$ saline subphase held in a perspex trough $(1 \times 5.2 \times 12 \mathrm{~cm})$. The recording system was an attached Polaroid type 87 camera. Vertical movement of the platinum plate by a change in surface tension produced a proportional deflection of a small mirror attached to the torsion arm and, consequently, move-

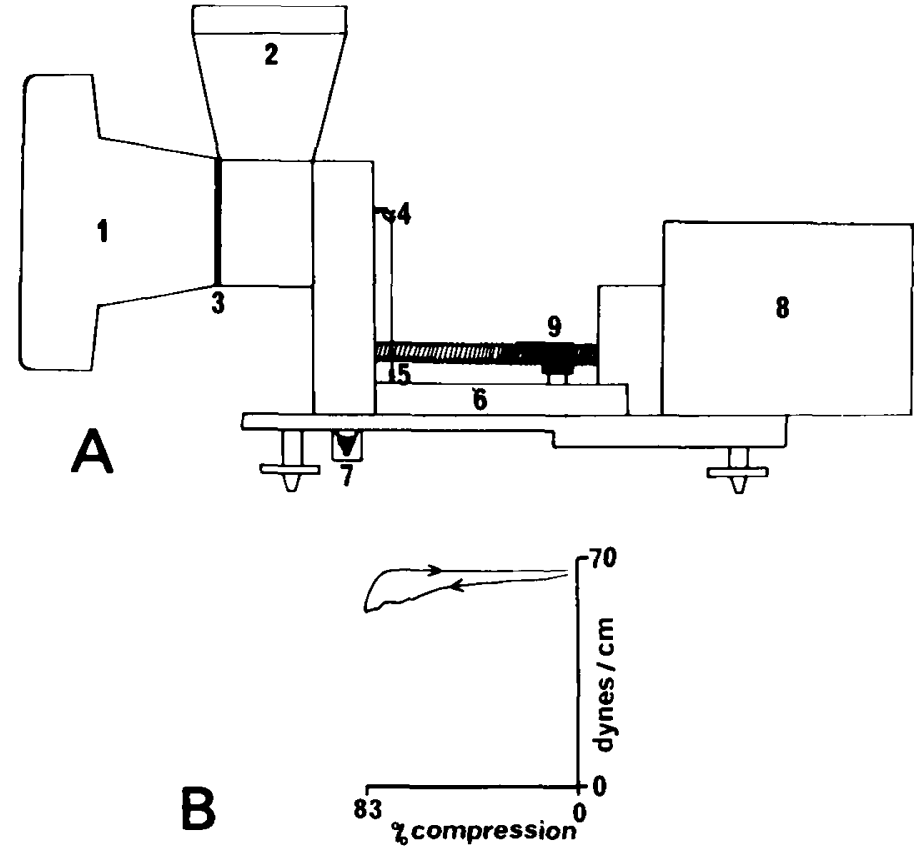

Fig. 1. $a$, surface tension balance. 1 , Polaroid camera for continuous recording of surface tension; 2 , manual reading scale; 3 , shutter; 4 , balance arm; 5. platinum plate dipping in saline; 6 , perspex trough; 7 , lamp; 8 , motor; 9 , perspex barrier to compress surface. $b$, continuous recording of surface tension on compression and expansion of $18 \mu \mathrm{l}$ of lung wash from control rabbit.

ment of a spot of light reflected onto the film (Fig. $1 b$ ). Therefore, one axis of the film was surface tension and was calibrated by adding weights ( 50 to $300 \mathrm{mg}$ ) to the platinum plate. The surface was compressed by $83 \%$ by means of a perspex barrier driven by a motor at the rate of $1 \mathrm{~cm} / \mathrm{min}$ and then expanded to the original dimensions. This movement produced a proportional deflection on the other axis of the film. A calibration curve was obtained by adding 6 to $11 \mu \mathrm{g}$ of DPPC standard in chloroform/methanol (3/ $\mathrm{I} ; \mathrm{v} / \mathrm{v})$ to the saline surface using a micropipet and $5 \mathrm{~min}$ later measuring the surface pressure at $83 \%$ compression relative to the surface tension of the surface-swept saline solution. The surface pressures produced by 6 to $18 \mu \mathrm{l}$ of saline lung washes were obtained in a similar manner 15 min after addition to the surface (Fig $1 b$ ). The surface activity of lung washes was calculated in DPPC equivalents in $\mathrm{mg} / \mathrm{g}$ of dry lung weight.

Statistical analysis was by analysis of variance (17) or MannWhitney $U$ test (30).

The drugs and chemicals used and the suppliers (parentheses) were: atropine sulfate, epinephrine hydrogen tartrate (British Drug Houses); oxotremorine (R. Emmanuel Ltd.); d-propranolol, dlpropranolol hydrochloride (Imperial Chemical Industries); dl-dipalmitoyl phosphatidylcholine (Sigma Chemical Co.).

\section{RESULTS}

In control experiments $(n=5)$, it was found that 6 washes removed $95.7 \pm 0.7 \%$ (mean \pm S.E.) of the PC that could be removed with 12 washes. The total PC content of 6 washes was not significantly different $(2 P>0.05$; Mann-Whitney $U$ test) whether the interval was 5 or $30 \mathrm{~min}$ between successive washes.

Thirty min after the IP injection of oxotremorine $(0.2 \mathrm{mg} / \mathrm{kg})$, the $\mathrm{PC}$ content of the 6 pooled lung washes was approximately twice that of saline-injected control rabbits (Table 1). Atropine (2 $\mathrm{mg} / \mathrm{kg}$ ), dl-propranolol ( $\mathrm{l} \mathrm{mg} / \mathrm{kg}$ ), or d-propranolol (I mg/ $\mathrm{kg}$ ) were given IP at $40 \mathrm{~min}$ and oxotremorine at $30 \mathrm{~min}$ before killing. The antagonists had no effect themselves on the lung wash PC content. Atropine and dl-propranolol but not d-propranolol abolished the rise in lung wash PC content induced by oxotremorine. 
Table 1. PC content of lung washes and residual lung tissue from neonatal rabbits ${ }^{1}$

\begin{tabular}{|c|c|c|c|c|c|}
\hline \multirow{2}{*}{ Treatment } & \multirow{2}{*}{ Dose } & \multirow{2}{*}{$\begin{array}{l}\text { Time treatment } \\
\text { to killing (min) }\end{array}$} & \multicolumn{3}{|c|}{ PC contents (mg/g dry lung wt) } \\
\hline & & & Lung wash & Residual lung tissue & $n$ \\
\hline Saline & & 30 & $25.7 \pm 1.9^{a, b .2}$ & $72.6 \pm 6.0^{a}$ & 5 \\
\hline Oxotremorine & $0.2 \mathrm{mg} / \mathrm{kg}$ & 30 & $50.5 \pm 2.9^{a, c, d, e}$ & $71.8 \pm 6.8$ & 7 \\
\hline Atropine & $2 \mathrm{mg} / \mathrm{kg}$ & 40 & $20.8 \pm 2.0$ & $104.4 \pm 18.5^{a}$ & 5 \\
\hline Atropine & $2 \mathrm{mg} / \mathrm{kg}$ & 40 & & & \\
\hline+ & & & $21.5 \pm 1.1^{c}$ & $83.4 \pm 15.3$ & 5 \\
\hline Oxotremorine & $0.2 \mathrm{mg} / \mathrm{kg}$ & 30 & & & \\
\hline dl-Propranolol & $1 \mathrm{mg} / \mathrm{kg}$ & 40 & $32.9 \pm 8.4$ & $70.9 \pm 4.6$ & 5 \\
\hline dl-Propranolol & $1 \mathrm{mg} / \mathrm{kg}$ & 40 & & & \\
\hline+ & & & $20.4 \pm 1.7^{d}$ & $85.4 \pm 7.6$ & 5 \\
\hline Oxotremorine & $0.2 \mathrm{mg} / \mathrm{kg}$ & 30 & & & \\
\hline d-Propranolol & $1 \mathrm{mg} / \mathrm{kg}$ & 40 & $23.9 \pm 2.6$ & $65.1 \pm 5.3$ & 5 \\
\hline d-Propranolol & $1 \mathrm{mg} / \mathrm{kg}$ & 40 & & & \\
\hline+ & & & $42.6 \pm 6.2$ & $78.3 \pm 6.1$ & 5 \\
\hline Oxotremorine & $0.2 \mathrm{mg} / \mathrm{kg}$ & 30 & & & \\
\hline Epinephrine & $20 \mu \mathrm{g} / \mathrm{kg}$ & 30 & $40.9 \pm 6.8$ & $55.5 \pm 6.6$ & 4 \\
\hline Epinephrine & $50 \mu \mathrm{g} / \mathrm{kg}$ & 30 & $78.0 \pm 14.8^{b J}$ & $76.4 \pm 13.1$ & 5 \\
\hline dl-Propranolol & $1 \mathrm{mg} / \mathrm{kg}$ & 40 & & & \\
\hline+ & & & $20.4 \pm 3.4^{\prime}$ & $68.1 \pm 2.7$ & 5 \\
\hline Epinephrine & $50 \mu \mathrm{g} / \mathrm{kg}$ & 30 & & & \\
\hline Adrenalectomy & & 45 & $29.5 \pm 5.3$ & $63.0 \pm 7.3$ & 4 \\
\hline Adrenalectomy & & 45 & & & \\
\hline+ & & & $26.9 \pm 4.5^{\circ}$ & $73.9 \pm 1.2$ & 4 \\
\hline Oxotremorine & $0.2 \mathrm{mg} / \mathrm{kg}$ & 30 & & & \\
\hline
\end{tabular}

As expected, oxotremorine also produced tremors, salivation, and hypothermia. Only atropine produced clear antagonism of these effects.

Epinephrine (20 or $50 \mu \mathrm{g} / \mathrm{kg}$ ) was given SC $30 \mathrm{~min}$ before killing. The higher dose produced a significant $(2 P<0.001$; analysis of variance) three-fold increase in lung wash PC content (Table 1). This effect was antagonized by dl-propranolol (d-propranolol was not tested).

To further investigate the possible indirect action of oxotremorine, this drug or saline was given $15 \mathrm{~min}$ following bilateral adrenalectomy, and the animals were killed $30 \mathrm{~min}$ later. The PC content of lung washes was not altered $45 \mathrm{~min}$ after bilateral adrenalectomy compared to intact controls but the action of oxotremorine was abolished (Table 1).

The residual lung tissue content of PC in saline controls was significantly greater $40 \mathrm{~min}$ following atropine $(2 \mathrm{mg} / \mathrm{kg})$ pretreatment but not significantly different in any of the other experimental groups (Table 1). The total volume of saline washes withdrawn was not different between experimental groups. The total lung content of PC (lung wash plus lung tissue) after epinephrine (50 $\mu \mathrm{g} / \mathrm{kg}$ ) was $154.4 \pm 13.8 \mathrm{mg} / \mathrm{g}$ dry lung weight which was $55 \%$ greater $(2 P<0.001)$ than for controls $(98.3 \pm 7.2 \mathrm{mg} / \mathrm{g}$ dry lung weight).

Further qualitative chemical analysis of the lung washes from two saline and two oxotremorine- $(0.2 \mathrm{mg} / \mathrm{kg})$ pretreated rabbits showed that PC was the major phospholipid present, with only a small amount of phosphatidylserine which would cochromatograph with the PC on one-dimensional thin-layer chromatography. The main fatty acids present in the PC from the control rabbits were palmitic acid $(74.6 \%)$, myristic acid $(15.2 \%)$, and oleic acid (10.2\%; each value mean from 2 animals). The proportions were similar from the oxotremorine pretreated rabbits.

In further groups of rabbits, the surface activity of lung washes was assayed using the surface tension balance. The surface tension of saline was $69.8 \pm 1.5$ dynes $/ \mathrm{cm}$ (mean \pm S.E.; $n=10)$. There was a linear relationship between the amount of DPPC standard (6 to $11 \mu \mathrm{g}$ ) added to the surface of a saline subphase and the surface pressure produced. Injection of rabbits with oxotremorine $(0.2 \mathrm{mg} / \mathrm{kg} \mathrm{IP})$ or epinephrine $(50 \mu \mathrm{g} / \mathrm{kg} \mathrm{SC}) 30 \mathrm{~min}$ before killing
Table 2. Surface activity ${ }^{1}$ of lung washes from neonatal rabbits

\begin{tabular}{lcccc}
\hline \multicolumn{1}{c}{ Drug } & Dose & $\begin{array}{c}\text { Time injec- } \\
\text { tion to kill- } \\
\text { ing (min) }\end{array}$ & $\begin{array}{c}\text { Surface activity' } \\
(\mathrm{mg} / \mathrm{g} \text { dry lung wt) }\end{array}$ & $n$ \\
\hline Saline & & 30 & $42.8 \pm 2.0^{2.3 a, 3 b}$ & 5 \\
Oxotremorine & $0.2 \mathrm{mg} / \mathrm{kg}$ & 30 & $73.8 \pm 9.9^{a}$ & 5 \\
Epinephrine & $50 \mu \mathrm{g} / \mathrm{kg}$ & 30 & $72.2 \pm 10.2^{b}$ & 5 \\
\hline
\end{tabular}

'Surface activity measured on Wilhelmy surface tension balance in terms of equivalents of dipalmitoyl phosphatidylcholine.

${ }^{2}$ Mean \pm S.E.

${ }^{3}$ Superscripts $a$ and $b$, significantly different from controls $(2 P<0.05$; Mann Whitney $U$ test).

approximately doubled the surface activity, measured as DPPC equivalents, in lung washes compared to saline controls (Table 2). There was a significant $(2 P<0.05)$ and positive correlation $(r=$ 0.63 ) between PC content and surface activity in individual washes from these three groups.

Because oxotremorine and epinephrine could increase the PC content of lung washes in vivo, so their effects were studied in the isolated lung by a $10 \mathrm{~min}$ infusion via the pulmonary artery between the fifth and sixth washes. The PC contents of the sixth wash following saline $(2.0 \pm 0.3 \mathrm{mg} / \mathrm{g} ; n=5)$ or $0.34 \mu \mathrm{g} / \mathrm{ml}$ oxotremorine $(0.9 \mathrm{mg} / \mathrm{g} ; n=2)$ were less than their respective fifth washes $(2.8 \pm 0.5$ and $1.5 \mathrm{mg} / \mathrm{g})$. However, following $3.4 \mu \mathrm{g} / \mathrm{ml}$ epinephrine, the PC content was significantly raised $(2 P<0.05$; Mann Whitney $U$ test) from $3.7 \pm 0.6 \mathrm{mg} / \mathrm{g}$ (fifth wash) to $4.8 \pm$ $0.8 \mathrm{mg} / \mathrm{g}$ (sixth wash; $n=6$ ).

\section{DISCUSSION}

These experiments demonstrated that the PC content and surface activity of lung washes of neonatal rabbits was increased only $30 \mathrm{~min}$ after the injection of oxtremorine or epinephrine. The simplest explanation of these observations is that these drugs increased the secretion of lung surfactant into alveoli.

Lung surfactant is defined by its ability to lower surface tension 
at the air-liquid interface (15). Saline washes (6 to $18 \mu \mathrm{l}$ ) of neonatal rabbit lungs produced measurable surface pressures on compression and so the surface activity could be assayed quantitatively. Because DPPC is thought to be the principal component of lung surfactant $(14,15,21)$, this was used as the standard for both chemical and surface activity assays. Increased PC content or surface activity of washes after oxotremorine or epinephrine does not necessarily imply that the DPPC content was increased However, a combination of two-dimensional thin-layer chromatography and gas-liquid chromatography suggested that palmitic acid formed about $75 \%$ of the fatty acids in the PC spot, and this proportion was similar after oxtremorine. This proportion is slightly higher than the findings of others in neonatal rabbits $(14$, 28 ). The results suggest that the major $P C$ present in the lung washes was DPPC. Also, there was a significant positive correlation between PC content and surface activity of lung washes from oxotremorine, epinephrine, and control treated rabbits. Therefore, we suggest that assay of PC content of lung washes is a reasonable measure of surfactant content.

A major criterion that one is studying stimulation of a secretory rather than a biosynthetic process is the measurement of an increase in the concentration of the secreted substance in an appropriate extracellular space a short time interval after application of the stimulus. The finding of increased PC content and surface activity of lung washes only $30 \mathrm{~min}$ after oxotremorine and epinephrine in vivo and increased PC content of washes only 15 min after commencement of epinephrine perfusion in vitro are more direct evidence of stimulation of secretion than the results of most earlier workers $(7,8,12,18,25,26,34)$ who have used time intervals of more than $3 \mathrm{hr}$ between stimulus and measurement.

The increase in surfactant in lung washes after oxotremorine and epinephrine in vivo and the abolition of these effects with atropine and dl-propranolol, respectively, provide further support for the modulation of surfactant secretion via muscarinic receptors and $\beta$-adrenoceptors (see "Introduction"). The effect of oxtremorine in vivo was antagonized by dl-propranolol and acute adrenalectomy. Also, oxotremorine was ineffective in increasing the lung wash PC contents in the isolated, perfused, and ventilated lung in two experiments and as published previously (1), but epinephrine could increase lung wash PC contents. These results therefore suggest that oxotremorine does not act directly on type 2 pneumocytes to cause secretion and support the hypothesis that pilocarpine, another muscarinic agonist, also acts indirectly (8). Rather, the results suggest that oxotremorine increases catecholamine secretion from the adrenal medulla which then act on $\beta$ adrenoceptors in the lung to produce surfactant secretion. $\mathrm{Re}$ cently, oxotremorine has been shown to increase norepinephrine and epinephrine plasma concentrations in the adult rat (33). The resolved d-propranolol was also used as this isomer has the local anaesthetic properties of dl-propranolol but is less potent as a $\beta$ adrenoceptor antagonist $(20)$. The lack of antagonism by d-propranolol of oxotremorine's effects provide further support for oxotremorine's action via $\beta$-adrenoceptors rather than by other mechanisms. In most tissues where there is autonomic control of secretory processes, this is mediated by muscarinic receptors rather than by adrenoceptors. However, there is a precedent in that renin release from the kidney is modulated by $\beta$-adrenoceptors (10).

It was anticipated that the increased lung wash content of PC after oxotremorine and epinephrine would be reflected in a proportionate decrease in the PC content of the residual lung tissue; this was not the case. In lung tissue, compared to lung washes, a greater proportion of the PC's are unsaturated, non surface active and form cell membranes $(14,28)$. This could have obscured any changes in the saturated, surface active $P C$ in the residual lung tissue. Because the total lung content of $\mathrm{PC}$ was $55 \%$ greater than control $30 \mathrm{~min}$ after epinephrine $(50 \mu \mathrm{g} / \mathrm{kg})$, this must reflect increased biosynthesis. Our results and those of others $(8,11,12$, $18,24,26,34)$ provide evidence for $\beta$-adrenoceptor control of secretion. We therefore suggest that increased biosynthesis in vivo was secondary to increased secretion. Primary control of secretory rate with feedback control of biosynthesis rate is a common feature where substances are stored in a granular form before secretion (22). Measurements of turnover time after drug treatment are necessary to investigate this important hypothesis further.

The absence of an alteration in lung wash PC content after atropine, dl-propranolol or adrenalectomy suggest little tonic activity via muscarinic receptors or $\beta$-adrenoceptors in causing a regular secretion of lung surfactant in neonatal rabbits. We are as yet unable to explain the increased residual lung tissue PC content after atropine alone. It is possible that a 40 -min interval between injection and killing was too short to demonstrate any effects of the antagonists on a tonically active system. Oyarzún and Clements $(25,26)$ demonstrated a slightly decreased phospholipid content of lung washes in adult, lightly anesthetised rabbits $2 \mathrm{hr}$ after dl-propranolol but no change following atropine. It is possible that muscarinic receptor and $\beta$-adrenoceptor mediated control of lung surfactant secretion is usually minimal but may be more important under certain situations such as during increased ventilation $(13,25,26)$ and at birth.

\section{CONCLUSION}

The PC content of lung washes of neonatal rabbits was increased $30 \mathrm{~min}$ after oxotremorine. This effect was antagonized by atropine, dl-propranolol, acute adrenalectomy but not by d-propranolol. The PC content of lung washes was also increased $30 \mathrm{~min}$ after epinephrine, the effect being antagonized by dl-propranolol. Oxotremorine and epinephrine increased the surface activity in lung washes. Epinephrine, but not oxotremorine, increased the PC content of lung washes of isolated, perfused, and ventilated lungs. The results suggest that oxotremorine and epinephrine increased the secretion of surfactant into alveoli. Oxotremorine probably acts indirectly by increasing secretion of catecholamines from the adrenal medulla which then act on $\beta$-adrenoceptors in the lung. The total lung tissue content of PC was increased after epinephrine suggesting that biosynthesis was stimulated secondarily to increased secretion.

\section{REFERENCES AND NOTES}

1. Abdellatif, M. M., and Hollingsworth. $M$.: The in vitro and in vivo effects of oxotremorine on the phosphatidylcholine content of washes of neonatal rabbit lungs. Br. J. Pharmacol., 61: 502P (1977).

2. Abdellatif, M. M., and Hollingsworth, M.: Mediation by adrenaline of lung surfactant secretion induced by oxotremorine in neonatal rabbits. Br. J. Pharmacol., 66: 142P (1979).

3. Ahmed, A., and Chiswick, M. L.: Origin of osmiophilic inclusion bodies in type II pneumocytes. J. Pathol., 113: 161 (1974).

4. Askin, F. B., and Kuhn, C.: The cellular origin of pulmonary surfactant. Lab. Invest., 25: 260 (1971)

5. Bensch, K., Schaeffer, K., and Avery, M. E.: Granular pneumocytes: electron microscopic evidence of their endocrine function. Science (Wash. D. C.), 145: 1318 (1964).

6. Chen, P. S., Toribara, T. Y., and Warner, H.: Microdetermination of phosphorus. Anal. Chem., 28: 1756 (1956).

7. Corbet, A. J. S., Flax, P., and Rudolph, A. J.: Reduced surface tension in lungs of fetal rabbits injected with pilocarpine. J. Appl. Physiol., 41: 7 (1976).

8. Corbet, A. J. S., Flax, P., and Rudolph, A. J.: Role of autonomic nervous system controlling surface tension in fetal rabbit lungs. J. Appl. Physiol., 43: 1039 (1977).

9. Cox, B., and Hecker. S. E.: Investigation of the mechanism of action of oxotremorine on the guinea-pig isolated ileum preparation. Br. J. Pharmacol., 41: 19 (1971).

10. Davis, J. O.: Control of renin release. In: J. O. Davis, J. H. Laragh, and A Selwyn: Hypertension. Mechanisms, diagnosis and management. pp. 35-45 (HP Publishing, New York, 1977).

11. Dobbs, L., and Mason, R.: Terbutaline-induced secretion of disaturated phosphatidylcholine from pulmonary alveolar type II cells. J. Cell Biol., 75: 375 a (1977).

12. Enhorning, G., Chamberlain, D., Contreras, C., Burgoyne, R., and Robertson. B.: Isoxsuprine-induced release of pulmonary surfactant in rabbit fetuses. Am J. Obstet. Gynecol., 129: 197 (1977).

13. Faridy, E. E.: Effect of distension on release of surfactant in excised dog's lungs. Respir. Physiol., 27: 99 (1976).

14. Gluck, L., Landowne, R. A., and Kulovich, M. V.: Biochemical development of surface activity in mammalian lung. III. Structural changes in lung lecithin during development of the rabbit fetus and newborn. Pediatr. Res., 4: 352 (1970).

15. Goerke, J.: Lung surfactant. Biochim. Biophys. Acta, 344: 241 (1974).

16. Goldenberg. V. E., Buckingham. S., and Sommers, S. C.: Pilocarpine stimulation of granular pneumocyte secretion. Lab. Invest., 20: 147 (1969). 
17. Goldstein, A.: Biostatics: an introductory text. (Macmillan, New York, 1967)

18. Hayden, W., Olson, E. B., and Zachman. R. D.: Effect of maternal isoxsuprine on fetal rabbit lung biochemical maturation. Am. J. Obstet. Gynecol., 129: 691 (1977).

19. Hill, C. M.: The determination of the fatty acid profile of lecithin from human amniotic fluid and the pharyngeal aspirate of the new-born. J. Physiol. (Lond), 257: 15P (1976).

20. Howe, R., and Shanks, R. G.: The optical isomers of propranolol. Nature (Lond.). 210: 1336 (1966).

21. King, R. J.: The surfactant system of the lung. Fed. Proc., 33: 2238 (1974).

22. Lacy, P. E.: Endocrine secretory mechanisms. Am. J. Pathol., 79: 170 (1975).

23. Morgan. T. E., and Morgan. B. C.: Surfactant synthesis, storage and release by alveolar cells. In: C. A. Villee, D. B. Villee, J. Zuckerman: Respiratory Distress Syndrome. pp. 117-127 (Academic Press Inc.. New York, 1973).

24. Olsen, D. B.: Neurohumoral-hormonal secretory stimulation of pulmonary surfactant in the rat. Physiologist, 15: 230 (1972).

25. Oyarzún, M. J., and Clements. J. A.: Ventilatory and cholinergic control of pulmonary surfactant in the rabbit. J. Appl. Physiol., 43: 39 (1977).

26. Oyarzun, M. J., and Clements. J. A.: Control of lung surfactant by ventilation. adrenergic mediators and prostaglandins in the rabbit. Am. Rev. Respir. Dis., 117: 879 (1978).

27. Pysher, T. J., Konrad, K. D., and Reed, G. B.: Effects of hydrocurtisone and pilocarpine on fetal rat lung explants. Lab. Invest., 37: 588 (1977).

28. Rooney, S. A.. and Gobran, L. l.: Alveolar lavage and lavaged lung tissue phosphatidylcholine composition during fetal rabbit development. Lipids. 12: 1050 (1977)

29. Ryan, U. S., Ryan, J. W., and Smith, D. S.: Studies on the mode of release of lamellar bodies. Tissue Cell, 7: 587 (1975)

30. Siegel, S.: Nonparametric statistics for the behavioural sciences. (McGraw-Hill Book Co., New York, 1956)

31. Smith, B. T.: Cell line A549: a model system for the study of alveolar type II cell function. Am. Rev. Respir. Dis., 1/5: 285 (1977)

32. Trifaró. J. M.: Common mechanisms of hormone secretion. Ann. Rev. Pharmacol., 17: 27 (1977).

33. Weinstock. M., Zavadil, A. P., Rosin. A. J.. Chiueh. C. C., and Kopin. I. J.: The role of peripheral catecholamines in oxotremorine tremor in the rat and it antagonism by beta adrenoceptor blocking agents. J. Pharmacol. Exp. Ther.. 206: 91 (1978)

34. Wyszogrodski, I., Taeusch, H. W., and Avery, M. E.: Isoxsuprine-induced alterations of pulmonary pressure-volume relationships in premature rabbits. Am. J. Obstet. Gynecol., 119: 1107 (1974).

35. The authors appreciate the help of Dr. C. Hill, Department of Obstetrics and Gynaecology, St. Mary's Hospital, Manchester, Professor B. R. Pullan. Department of Medical Biophysics, Manchester, and ICI, Pharmaceuticals Division for the gifts of d-propranolol and dl-propranolol.

36. Requests for reprints should be addressed to: $\mathrm{M}$. Hollingsworth, Ph.D., Departments of Pharmacology. Materia Medica and Therapeutics. University of Manchester Medical School. Stopford Building, Oxford Rd.. Manchester M13 9PT, England.

37. This research was supported by the Egyptian Education Bureau: Duchess of York Friends of the Hospital: Smith. Kline and French Foundation, and the Children's Research Fund.

38. Received for publication April 16, 1979.

39. Accepted for publication November 28. 1979 